\section{LIBROS Y REVISTAS RECIBIDOS}

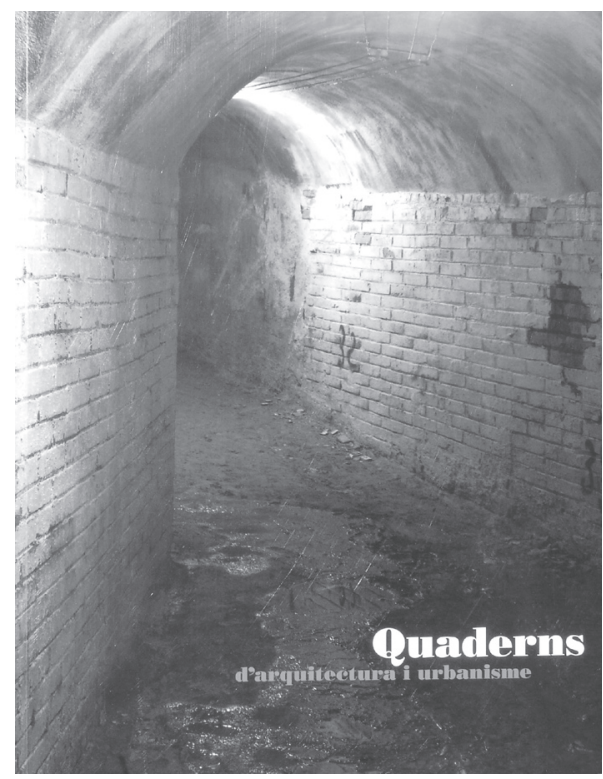

\section{TeCTónica $\mathbf{N}^{\circ} \mathbf{2 1}$}

Carlos Quintans, José María Marzo, directores ATC Ediciones, S. L., Madrid

Bimensual

120 páginas, $21 \times 29,5 \mathrm{~cm}$, color

Julio de 2006

Texto castellano

Web www.tectonica.es

Con un prólogo muy interesante titulado Las instalaciones y la arquitectura, que recorre el s. XX deteniéndose con más detalle en su segunda mitad, este número vuelve a ser un ejemplar de orientación y consulta para profesionales y estudiantes.

Sin embargo, las obras de arquitectura elegidas, si bien correctas, son de expresión muy cercana en si mismas a una instalación. Tal vez hubiese sido oportuno incorporar algún caso en los que el observador, además de admirar la arquitectura, se preguntara ¿qué pasa con las instalaciones?

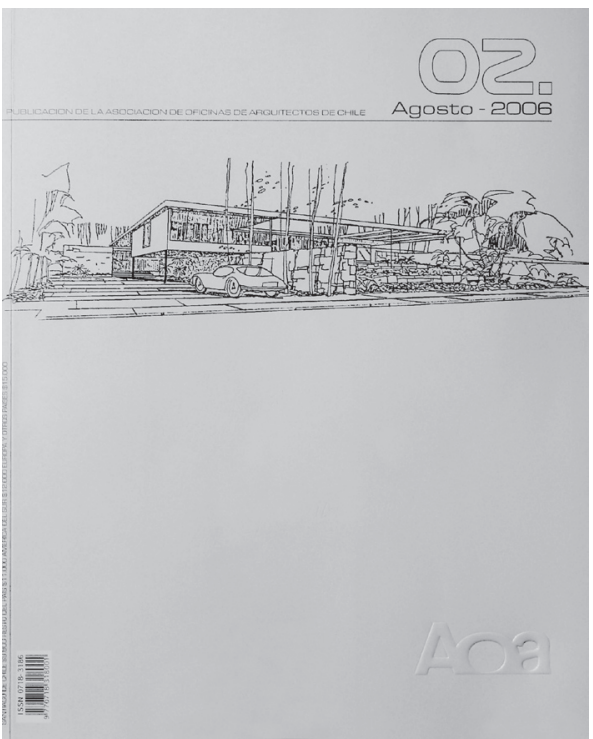

\section{$<$ Quaderns d'ARQuitectura I URBanisme}

Oriol Bohigas, redactor editorial

Collegi d'Arquitectes de Catalunya, Barcelona

Trimestral

150 páginas, $24 \times 31 \mathrm{~cm}$, color

Primavera 2006

Texto catalán / inglés / castellano

Webdgr@coac.net

En este número, con el que se inicia el período de un nuevo equipo editorial, la revista recupera una vitalidad prometedora con una estructura muy bien pensada en su variedad y profundidad de temas: nos encontramos con la arquitectura, sin retórica ni amaneramientos. Varias generaciones de buenos arquitectos firman los artículos publicados: Oriol Bohigas, Manuel de SoláMorales, Josep Parcerisa, Helio Piñón, María Rubert de Ventós y Joseph Quetglas, entre los que conocemos aquí en Chile. Uno siente que se recupera un prestigio que los arquitectos estamos perdiendo, en una revista sin pelos en la lengua.

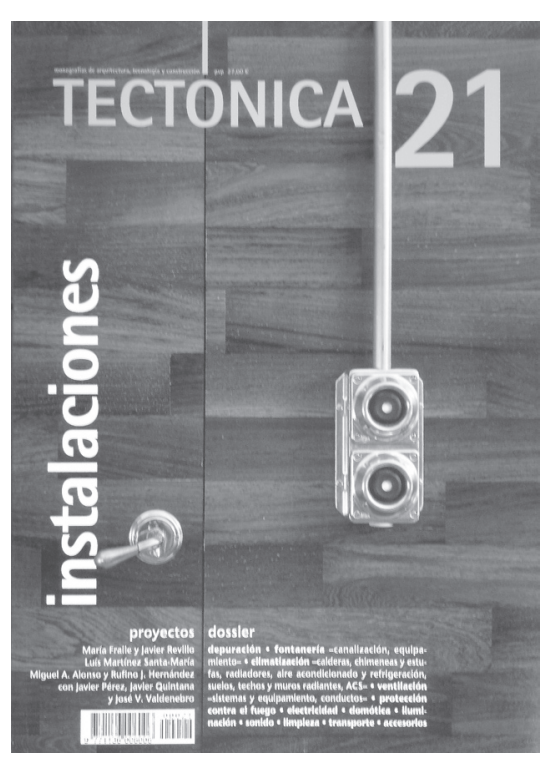

\section{AOA N $^{\circ} 2$}

David Rodríguez, director

Publicaciones AOA

Asociación de Oficinas de Arquitectos de Chile Cuatrimestral

109 páginas, $24 \times 29,7 \mathrm{~cm}$, color

Agosto de 2006

Texto castellano

Web info@aoa.c

El segundo número de la revista de la Asociación de Oficinas de Arquitectos ya permite ver con claridad su línea editorial orientada a la difusión de obras recientes construidas en Chile. Lo interesante es que el amplio catálogo de proyectos tiene un contrapunto en el reportaje que abre cada edición; una síntesis que presenta la obra de algún arquitecto chileno de mediados del s. XX. En el primer número, Emilio Duhart, esta segunda entrega incluye la necesaria revisión de la obra de Jaime Sanfuentes, concentrada en el barrio de Jardín de Este en Santiago: un conjunto consistente de viviendas que articula los valores espaciales de la Arquitectura Moderna con una modesta realidad constructiva.

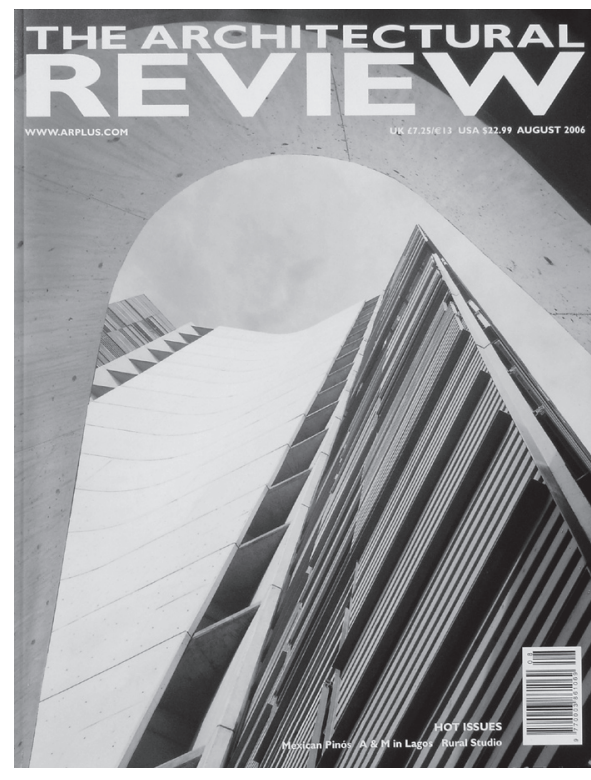

The Architectural Review N ${ }^{\circ} 1314$

Paul Finch, director

Emap Communications, Londres

90 páginas, $23 \times 29,5 \mathrm{~cm}$, color

Agosto de 2006

Texto inglés

Web www.arplus.com

Un edificio de oficinas de Carme Pinós en Guadalajara con una presencia "fuerte pero delicada" es la obra más interesante de un conjunto variado y de calidad.

Un pabellón para competencias náuticas en Valencia de David Chiperfield se agradece por su arquitectura no expresionista, después de tanto cachondeo de Calatrava. Además varias obras de interés, como un museo de Kengo Kuma en Tokio o una casa de temporada en Australia de Sean Godsell, que es un agradable reencuentro con volúmenes livianos y tranquilos. El lunar del número: una empingorotada tienda en Nueva York, derivada de las peores posibilidades que ofrece el diseño por computador. 